УДК 582.579.2:547.587.51

\title{
КУМАРИНЫ ИРИСА БОЛОТНОГО (IRIS PSEUDACORUS L.)
}

\author{
(ㄱ) В.Н. Ковалев, О.А. Михайленко“", С.В. Ковалев
}

Национальный фармацевтический университет, ул. Пушкинская, 53, Харьков, 61002 (Украина), e-mail: botanica@ukrfa.kharkov.ua

Представлены результаты выделения и установления структуры кумаринов из корневищ ириса болотного (Iris pseudacorus L.). На основании физико-химических свойств веществ, продуктов их химических превращений, данных УФ-, ИК-спектроскопии, сравнением со стандартными образцами идентифицировано: кумарин, умбеллиферон, эскулетин, скополетин, изоскополетин, герниарин, дафноретин. Из растений рода Iris L. кумарины выделены впервые.

Ключевые слова: Iris pseudacorus, ирис болотный, УФ-, ИК-спектроскопия, кумарины.

\section{Введение}

Несмотря на широкий арсенал лекарственных препаратов, применяемых на сегодняшний день в медицинской практике, особое место среди них занимают фитопрепараты ввиду их высокой фармакологической активности, малой токсичности, доступности и возможности длительного применения без существенных побочных явлений. Следовательно, поиск новых высокоэффективных отечественных фитопрепаратов на основе местного растительного сырья является целесообразным.

Среди огромного количества лекарственных растений, находящихся в арсенале современной фитотерапии, существуют виды, фармакологическая активность которых научно не подтверждена, но они с успехом используются в народной медицине разных стран на протяжении тысячелетий. Одним из них и является ирис болотный (Iris pseudacorus, Iridaceae). Ирис болотный широко распространен по территории Украины, большие запасы сырья представлены в Харьковской, Сумской, Полтавской и других областях [1-3]. Корневища применяют для лечения воспалительных заболеваний верхних дыхательных путей, мочеполовой системы, а также желудочно-кишечного тракта $[4,5]$. Листья и корневища накапливают преимущественно вещества фенольной природы: флавоноиды [5, 6], изофлавоноиды [7], дубильные вещества, ксантоны $[8,9]$. Целью данного исследования было выделение и установление структуры кумаринов из корневищ ириса болотного.

\section{Экспериментальная часть}

Растительный материал. Объектом исследования были корневища ириса болотного, заготовленные в Харьковской области, с. Борщевая, осенью 2010 г. Сырье сушили до воздушно-сухого состояния, упаковывали в тканевые мешки и хранили в сухом месте.

Общие экспериментальные условия. Качественный состав кумаринов в корневищах ириса болотного изучали с помощью общепринятых методов анализа.

Для химического анализа среднюю пробу сырья измельчали до размера частиц 2-3 мм. Для исследо-

Михайленко Ольга Александровна - ассистент кафедры ботаники, кандидат фармацевтических наук, e-mail: z_ola07@mail.ru

Ковалев Сергей Владимирович - доцент кафедры ботаники, доктор фармацевтических наук, e-mail: z_ola07@mail.ru

Ковалев Владимир Николаевич - профессор кафедры фармакогнозии, доктор фармацевтических наук, e-mail: z_ola07@mail.ru вания качественного состава фенольных соединений из подземных органов получали водно-спиртовое извлечение путем исчерпывающей экстракции $70 \%$ этанолом (в соотношении сырье - экстрагент $1: 50$ ) [10], а также экстрагировали сырье хлороформом в аппарате Сокслета до полного обесцвечивания экстрагента (исчерпывающая экстракция).

\footnotetext{
* Автор, с которым следует вести переписку.
} 
Для выявления кумаринов использовали бумажную хроматографию. Спирто-водный, хлороформный экстракты хроматографировали в системах растворителей: хлороформ (формамид 25\%); петролейний эфир (формамид 25\%); бензол (формамид 25\%). На хроматограммах кумарины обнаруживали по характерному свечению в УФ-свете при длине волны 365 нм до и после обработки хроматограмм парами аммиака, 10\% раствором натрий/калий гидроксида, 5\% спиртовым раствором диазотированной сульфаниловой кислоты [11].

Для очистки, разделения на фракции и выделения индивидуальных кумаринов применяли методы избирательной жидкостной экстракции, адсорбционной колоночной хроматографии на силикагеле, бумажной хроматографии, дробной кристаллизации.

Экстракиял сырья. Измельченное сырье (1 кг корневищ ириса болотного) экстрагировали 50\% этанолом в перколяторе в течение 24 ч. Процесс экстракции повторяли дважды в тех же условиях. Спиртоводное извлечение объединяли, фильтровали, упаривали на роторно-выпарительном аппарате до 0,7 л водного остатка, отстаивали в течении суток, отделяли надосадочную жидкость. Полученный экстракт последовательно обрабатывали хлороформом, этилацетатом и $н$-бутанолом. Полученные извлечения упаривали под вакуумом.

Качественный состав хлороформной, этилацетатной и бутанольной фракций исследовали методом двумерной бумажной хроматографии в системе растворителей: направление I - 1-бутанол - уксусная кислота вода (4 : $2: 1)$, направление II - $15 \%$ уксусная кислота.

Для колоночной хроматографии (КХ) использовали силикагель марки КСК (0,1 мкм), с пропусканием растворителя хлороформ - этанол 96\% (95:5). Перекристаллизацию веществ проводили из этанола. Бумажную хроматографию проводили на бумаге марки «Filtrak» FN-1, FN-2, FN-4. Пятна обнаруживали в УФ-свете после проявления парами аммиака.

Температуру плавления выделенных веществ определяли на блоке Кофлера (Franz Kьstner nqch K:G:Dresden; N.K. 70/3314k). Вещества для анализа высушивали под вакуумом (10-2 мм. рт. ст.) над $\mathrm{P}_{2} \mathrm{O}_{5}$ при температуре (110-115) ${ }^{\circ} \mathrm{C}$ в течение 5 ч. УФ-спектры снимали на спектрофотометре Carl Zeiss (Германия) Specord M-80 в кюветах с толщиной слоя 10 мм, ИК-спектры снимали на спектрометре Тensor 27, UR-20 (Германия) в таблетках калия бромида. В качестве ионизирующих и комплексообразующих добавок для установления структуры кумаринов применяли: 0,1 М раствор натрия этилата [12].

Деструкиия кумаринов йодоводородной кислотой [11]. 10-15 мг исследуемого вещества и 1-2 мл смеси (йодоводородная кислота и жидкий фенол) нагревали в колбе с обратным холодильником на песчаной водяной бане при $130{ }^{\circ} \mathrm{C}$ в течение 2 ч. Горячую реакционную смесь выливали в 10 мл холодной воды и экстрагировали хлороформом 5 раз по 10 мл. Объединенные хлороформные извлечения обрабатывали 2 раза по 5 мл 1\% раствором натрия карбоната, затем таким же количеством $2 \%$ раствора соляной кислоты, после чего промывали несколько раз водой и упаривали до сухого остатка, который растворяли в минимальном объеме этанола и оставляли для кристаллизации. Получили кристаллы с Т. пл. 65-68 ${ }^{\circ} \mathrm{C}$, которые не давали депрессии температуры плавления с достоверным образцом кумарина и имели одинаковые значения Rf в системе петролейный эфир (формамид 25\%).

\section{Обсуждение результатов}

Предварительные исследования проводили при помощи общепринятых методик. По результатам качественных реакций: лактонная проба и образование азокрасителя, красного окрашивания - установили наличие кумаринов в корневищах ириса болотного.

Идентификацию веществ проводили после хроматографирования спирто-водного и хлороформного экстрактов и по свечению в УФ-свете и окраске пятен до и после обработки хроматограмм хромогенными реактивами, а также по величинам Rf в сравнении со свидетелями. После обработки хромматограм $10 \%$ раствором натрий/калий гидроксидом, а также 5\% спиртовым раствором диазотированной сульфаниловой кислоты были выявлены пятна с голубой, фиолетовой, серо-зеленой, зеленой, желтой флуоресценцией. В результате предварительного фитохимического исследования в корневищах ириса болотного были установлены кумарин, дафноретин, эскулетин, умбеллиферон, герниарин, скополетин и изоскополетин.

После последовательной экстракции сырья органическими растворителями получены хлороформная, этилацетатная и бутанольная фракции. В результате хроматографического изучения хлороформной, этилацетатной фракции обнаружены вещества, которые имели голубую, фиолетовую, зелено-голубую флуоресценцию в УФ-свете и ранее были отнесены к кумаринам. Разделяли сумму кумаринов колоночной 
хроматографией на силикагеле, эллюировали хлороформом и спирто-хлороформными смесями. Фракции, содержащие индивидуальные вещества, объединяли, выпаривали до сухого остатка, растворяли в минимальном количестве этанола и оставляли для кристаллизации. Индивидуальность выделенных соединений контролировали двумерной хроматографией на бумаге.

Из хлорофорной фракции корневищ были выделены вещества (условно обозначенные) $\mathbf{1 , 2 , 3 , 4 , ~ и з ~}$

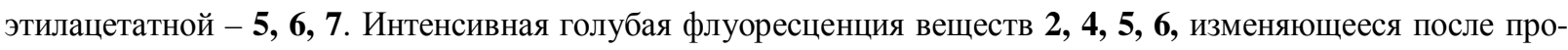
явления парами аммиака или спиртовым раствором щелочи, позволила предположить наличие в их структуре свободной гидроксильной группы при С-7.

Для установления структуры выделенных веществ использовали данные ИК-, УФ-, спектроскопии, сравнение с достоверно известными образцами. В ходе идентификации в необходимых случаях проводили деструкцию кумаринов йодоводородной кислотой.

Присутствие в УФ-спектре интенсивного максимума поглощения в области 310-345 нм и наличие в ИК-спектре полосы при 1710-1730 $\mathrm{cm}^{-1}$, характерной для валентных колебаний карбонильной группы $\alpha$-пирона, позволяет отнести вещества к производным кумарина [11].

Физико-химические свойства кумаринов, выделенных из кореневищ ириса болотного.

Вещество 1 (кумарин) - $\mathrm{C}_{9} \mathrm{H}_{6} \mathrm{O}_{2}$, кристаллы белого цвета, ИК-спектр $\left(\mathrm{KBr}, v, \mathrm{~cm}^{-1}\right): 1600(\mathrm{C}=\mathrm{C}) ; 1720$ $\left(\mathrm{C}=\mathrm{O}, \alpha\right.$-пирона); Т. пл. 67-68 ${ }^{\circ} \mathrm{C}$. При хроматографировании в хлороформе вещество 1 проявляется в виде слабо-голубого пятна, при проявлении раствором щелочи приобретает ярко-зеленую с голубым оттенком флуоресценцию.

Вещество 2 (умбеллиферон) - $\mathrm{C}_{9} \mathrm{H}_{6} \mathrm{O}_{3}$, белые игольчатые кристаллы, УФ-спектр (EtOH, $\lambda$ max, нM):

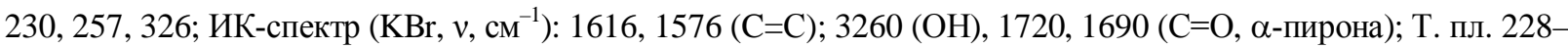
$230{ }^{\circ} \mathrm{C}$. Вещество 2 проявляется в УФ-свете в виде голубого пятна, флуоресценция которого усиливается после обработки раствором щелочи.

Вещество 3 (герниарин) - $\mathrm{C}_{10} \mathrm{H}_{8} \mathrm{O}_{3}$, кристаллы белого цвета, УФ-спектр (EtOH, $\lambda$ max, нм): 218, 320;

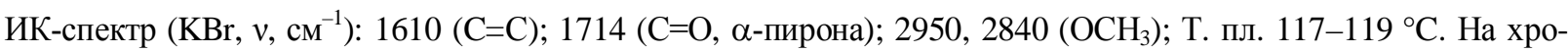
матограмме в системе петролейный эфир проявляется в виде пятна с бирюзово-зеленой флуоресценцией. Наличие в ИК-спектре полос поглощения при 2950, $2840 \mathrm{~cm}^{-1}$, характерных для метоксигруппы, позволяет предположить, что вещество 3 является метильным производным гидроксикумарина. При хроматографировании продукта дезметилирования в системе хлороформа со стандартным образцом умбеллиферона, их пятна совпадают и имеют одинаковое значение. Смешанная проба продукта дезметилирования с образцом умбеллиферона не давала депресии температуры плавления.

Вещество 4 (дафноретин) - $\mathrm{C}_{19} \mathrm{H}_{12} \mathrm{O}_{7}$, кристаллы белого цвета, УФ-спектр (EtOH, $\lambda$ max, нм): 218, 252; ИК-спектр (KBr, v, см$\left.{ }^{-1}\right)$ : $1650(\mathrm{C}=\mathrm{C}) ; 3344(\mathrm{OH}) ; 1720\left(\mathrm{C}=\mathrm{O}, \alpha\right.$-пирона); $2981\left(\mathrm{OCH}_{3}\right)$; Т. пл. $254-256^{\circ} \mathrm{C}$. Вещество 4 имеет фиолетовую окраску в УФ-свете после обратотки парами аммиака, интенсивность которой усиливается после обработки хроматограммы щелочью, а после обработки реактивом 5\% спиртовым раствором диазотированной сульфаниловой кислотой приобретает ярко-малиновую окраску. В продуктах термической деструкции в токе водорода хроматографический анализ продуктов расщепления показал наличие умбеллиферон и скополетина.

Вещество 5 (эскулетин) - $\mathrm{C}_{9} \mathrm{H}_{6} \mathrm{O}_{4}$, мелкие игольчатые кристаллы. УФ-спектр (EtOH, $\lambda_{\max }$, Hм): 230, 260, 300, 360; ИК-спектр (KBr, v, см $\left.{ }^{-1}\right)$ : 1610, $1590(\mathrm{C}=\mathrm{C})$; 3340, $3225(\mathrm{OH}), 1710,1690$ (С=O, $\alpha$-пирона); Т. пл. 164-165 ${ }^{\circ} \mathrm{C}$. Образование зеленой окраски вещества 5 при взаимодействии с раствором железа (III) хлорида, наличие в ИК-спектре полос поглощения в области 2680-2930 см-1 (фенольные ОН-группы) позволили предположить наличие орто-дигидроксигрупы. Метильное производное вещества 5 с Т. пл. 164$165{ }^{\circ} \mathrm{C}$ не дает депрессии температуры плавления с образцом скопарону.

Вещество 6 (скополетин) - $\mathrm{C}_{10} \mathrm{H}_{8} \mathrm{O}_{4}$, белые игольчатые кристаллы, УФ-спектр (EtOH, $\lambda$ max, нм):

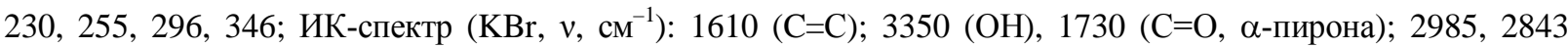
$\left(-\mathrm{OCH}_{3}\right)$; Т. пл. 202-204 ${ }^{\circ} \mathrm{C}$. Вещество 6 обладает ярко-голубой флуоресценцией при хроматографировании в системе хлороформ (25\% формамид). После обработки пятна раствором щелочи флуоресценция меняется на зеленовато-голубую.

Вешество 7 (изоскополетин) - $\mathrm{C}_{10} \mathrm{H}_{8} \mathrm{O}_{4}$, белые игольчатые кристаллы, УФ-спектр (ЕtOH, $\lambda$ max, нM):

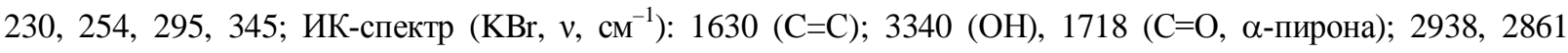


$\left(-\mathrm{OCH}_{3}\right) ;$ Т. пл. $185-187^{\circ} \mathrm{C}$. Вещество 7 имеет бледно-голубую флуоресценцию при хроматографировании в системе хлороформ (25\% формамид), в отличие от скополетина, а после обработки щелочью окрашивается в желтый цвет.

Таким образом, из хлороформной и этилацетатной фракции корневищ ириса болотного в индивидуальном состоянии было выделено 7 производных кумарина. На основании физико-химических свойств веществ, продуктов их химических превращений, данных УФ-, ИК-спектроскопии, сравнением со стандартными образцами идентифицированы: $\mathbf{1}$ - кумарин, $\mathbf{2}$ - умбеллиферон, $\mathbf{3}$ - герниарин, $\mathbf{4}$ - дафноретин, $\mathbf{5}$ - эскулетин, $\mathbf{6}$ - скополетин, $\mathbf{7}$ - изоскополетин. Кумарины впервые выделены из корневищ ириса болотного.

Кумарины проявляют разностороннюю биологическую активность. Для них характерна антимикробная, спазмолитическая, противоопухолевая активность [13], поэтому дальнейшее исследование этого класса соединение у растений рода Iris и создание препаратов на их основе является перспективным.

\section{Bbl6odbl}

1. Методом колоночной хроматографии на силикагеле из хлороформной и этилацетатной фракций корневищ ириса болотного было выделено семь производных кумарина.

2. Структура выделенных соединений установлена на основании физико-химических свойств веществ, продуктов их химических превращений, хроматографическими, спектральными методами и сравнением с достоверно известными образцами. Из корневищ ириса болотного выделены кумарины: кумарин, умбеллиферон, эскулетин, скополетин, изоскополетин, герниарин, дафноретин.

3. Из растений рода Iris L. кумарины выделены впервые.

\section{Список литературь}

1. Mosyakin S.L., Fedoranchuk M.M. Vascular plants of Ukraine. A nomenclatural checklist / Ed. S.L. Mosyakin, Kiev, 1999. $346 \mathrm{p}$.

2. Определитель высших растений Украины / под ред. Ю.Н. Прокудина, Б.В. Заверуха, В.И. Чопик. Киев, 1987. C. 404-405.

3. Czerepanov S.K. Vascular plants of Russia and adjacent states (The former USSR). Cambridge University Press, 2007. $532 \mathrm{p}$.

4. Кортиков В.Н., Кортиков А.В. Полная энциклопедия лекарственных растений. Ростов-на-Дону, 2008, 800 с.

5. Khare C.P. Indian medicinal plants. Berlin, Heidelberg: Springer - Verlag, 2007. 836 p.

6. Tsukasa I. Flavonoids of the genus Iris; structures, distribution and function // Ann. Tsukuba Bot. Gard, 1998. Vol. 17, Pp. 147-183.

7. Boland G.M., Dervilla M.X. Donnelly Isoflavonoids and related compounds // Natural Product Reports. 1998. Pp. 241-260.

8. Затыльникова О.А., Ковалев С.В. Фитохимическое изучение Iris pseudacorus // Фармация Казахстана: интеграция науки, образования и производства: материалы межд. научн.-практ. конф. Шимкент, 2009, С. 225-228.

9. Williams Ch.A., Harborne J.B., Colasante M. Flavonoid and xanthone patterns in bearded Iris species and the pathway of chemical evolution in the genus // Biochemical Systematics and Ecology. 1997. Vol. 25, N4. Pp. 309-325.

10. Гарник Т.П. Сучасні технології виробництва фітозасобів та перспективи фітотерапії // Фітотерапія. Часопис. 2008. №1. C. 59-63.

11. Кузнецова Г.А. Природные кумарины и фурокумарины, Л., 1967. 248 с.

12. Максютина Н.П., Литвиненко В.И. Методы выделения и исследования флавоноидных соединений // Фенольные соединения и их биологические функции. М., 1968, С. 7-26.

13. Aoife Lacy, Richard O'Kennedy. Studies on coumarins and coumarin-related compounds to determine their therapeutic role in the treatment of cancer // Current Pharmaceutical Design. 2004. Vol. 10, Pp. 3797-3811.

Поступило в редакциию 2 июля 2012 г. 


\section{Kovalev V.N., Mikhailenko O.A. , Kovalev S.V. COUMARINS OF YELLOW IRIS (IRIS PSEUDACORUS L.)}

National University of Pharmacy, ul. Pushkinskaia, 53, Kharkiv, 61002 (Ukraine), e-mail: botanica@ukrfa.kharkov.ua

The results of the isolation and structure determination of coumarins from the rhizomes of yellow iris (Iris pseudacorus L.). On the basis of physical and chemical properties of substances, products of chemical reactions, the data of UV, IR spectroscopy, by comparison with standard samples identified: coumarin, umbelliferone, esculetin, scopoletin, izoskopoletin, gerniarin, dafnoretin. Of the genus Iris L. coumarins isolated for the first time.

Keywords: Iris pseudacorus, yellow iris, UV, IR spectroscopy, coumarins.

\section{References}

1. Mosyakin S.L., Fedoranchuk M.M. Vascular plants of Ukraine. A nomenclatural checklist / Ed. S.L. Mosyakin, Kiev, 1999, $346 \mathrm{p}$.

2. Opredelitel' vysshikh rastenii Ukrainy. Ed. Iu.N. Prokudin, B.V. Zaverukha, V.I. Chopik. [Determinant of higher plants in Ukraine]. Kiev, 1987, pp. 404-405. (in Russ.).

3. Czerepanov S.K. Vascular plants of Russia and adjacent states (The former USSR), Cambridge University Press, 2007, 532 p.

4. Kortikov V.N., Kortikov A.V. Polnaia entsiklopediia lekarstvennykh rastenii. [Complete Encyclopedia of Medicinal Plants]. Rostov-on-Don, 2008, 800 p. (in Russ.).

5. Khare C.P. Indian medicinal plants. Berlin, Heidelberg: Springer - Verlag, 2007, 836 p.

6. Tsukasa I. Ann. Tsukuba Bot. Gard, 1998, vol. 17, pp. 147-183.

7. Boland G.M., Dervilla M.X. Natural Product Reports, 1998, pp. 241-260.

8. Zatyl'nikova O.A., Kovalev S.V. Farmatsiia Kazakhstana: integratsiia nauki, obrazovaniia i proizvodstva: ma-terialy mezhd. nauchn.-prakt. konf. [Pharmacy Kazakhstan: the integration of science, education and industry: proceedings of the international conference].Shymkent, 2009, pp. 225-228. (in Russ.).

9. Williams Ch.A., Harborne J.B., Colasante M. Biochemical Systematics and Ecology, 1997, vol. 25, no. 4, pp. 309-325.

10. Garnyk T.P. Fitoterapija, 2008, no. 1, pp. 59-63. (in Ukr.).

11. Kuznetsova G.A. Prirodnye kumariny i furokumariny. [Natural coumarins furokumariny]. Leningrad, 1967, 248 p. (in Russ.).

12. Maksiutina N.P., Litvinenko V.I. Fenol'nye soedineniia i ikh biologicheskie funktsii. [Phenolic compounds and their biological functions]. Moscow, 1968, pp. 7-26. (in Russ.).

13. Lacy A., O’Kennedy R. Current Pharmaceutical Design, 2004, vol. 10, pp. 3797-3811.

Received Jule 2, 2012

Revised October 1, 2012

\footnotetext{
* Corresponding author.
} 
